\title{
Review Article \\ Retinal Diseases Associated with Oxidative Stress and the Effects of a Free Radical Scavenger (Edaravone)
}

\author{
Tomomi Masuda, Masamitsu Shimazawa, and Hideaki Hara \\ Molecular Pharmacology, Department of Biofunctional Evaluation, Gifu Pharmaceutical University, Gifu, Japan \\ Correspondence should be addressed to Masamitsu Shimazawa; shimazawa@gifu-pu.ac.jp
}

Received 18 October 2016; Accepted 20 December 2016; Published 18 January 2017

Academic Editor: Silvana Hrelia

Copyright ( 2017 Tomomi Masuda et al. This is an open access article distributed under the Creative Commons Attribution License, which permits unrestricted use, distribution, and reproduction in any medium, provided the original work is properly cited.

Oxidative stress plays a pivotal role in developing and accelerating retinal diseases including age-related macular degeneration (AMD), glaucoma, diabetic retinopathy (DR), and retinal vein occlusion (RVO). An excess amount of reactive oxygen species (ROS) can lead to functional and morphological impairments in retinal pigment epithelium (RPE), endothelial cells, and retinal ganglion cells (RGCs). Here we demonstrate that edaravone, a free radical scavenger, decreased apoptotic cell death, oxidative damage to DNA and lipids, and angiogenesis through inhibiting JNK and p38 MAPK pathways in AMD, glaucoma, DR, and RVO animal models. These data suggest that the therapeutic strategy for targeting oxidative stress may be important for the treatment of these ocular diseases, and edaravone may be useful for treating retinal diseases associated with oxidative stress.

\section{Introduction}

Oxidative stress plays a pivotal role in the development and progression of multiple neurodegenerative disorders, including amyotrophic lateral sclerosis (ALS), Parkinson's disease (PD), Alzheimer's disease (AD), and Huntington disease (HD) $[1,2]$. Oxidative stress and neurodegeneration are also involved in several eye diseases, for which there are many published reports [3-5]. Aging, gene abnormalities, and excess exposure to exogenous oxidative stressors (e.g., a light exposure) increase oxidative stress in the eye. In this review, we describe the relationship between oxidative stress and retinal diseases, as well as the effects of the free radical scavenger, edaravone.

\section{Oxidative Stress}

2.1. Reactive Oxygen Species (ROS). Oxidative stress is caused by an imbalance between the antioxidant defense system and the production of reactive oxygen species (ROS), including superoxide anion $\left(\mathrm{O}_{2}{ }^{-\bullet}\right)$, hydroxyl radical $\left({ }^{\circ} \mathrm{OH}\right)$, hydrogen peroxide $\left(\mathrm{H}_{2} \mathrm{O}_{2}\right)$, and singlet oxygen $\left({ }^{1} \mathrm{O}_{2}\right)$. In particular, the superoxide anion $\left(\mathrm{O}_{2}{ }^{-\bullet}\right)$ and hydroxyl radical $\left({ }^{\circ} \mathrm{OH}\right)$ with an unpaired electron are also known as free radicals. Hydrogen peroxide exhibits a low reactivity, but it can penetrate cell membranes, including the inner and outer membranes of mitochondria. Therefore, hydrogen peroxide $\left(\mathrm{H}_{2} \mathrm{O}_{2}\right)$ can react with cellular iron and generate hydroxyl radicals, the most reactive form of oxygen, via the Fenton reaction: $\mathrm{H}_{2} \mathrm{O}_{2}$ $+\mathrm{Fe}^{2+} \rightarrow{ }^{\circ} \mathrm{OH}+{ }^{-} \mathrm{OH}+\mathrm{Fe}^{3+}[6]$.

These ROS are produced during the processes of several enzymatic and oxidation reactions. The mitochondrial respiratory chain is the main source of ROS production [7]. In the inner membrane of mitochondria, electrons are transported and oxygen is converted into water. Under hypoxic conditions, this process is not performed to completion, resulting in an increased production of superoxide anions $\left(\mathrm{O}_{2}^{-{ }^{-}}\right)$. Nicotinamide adenine dinucleotide phosphate (NADPH) oxidase (NOX) is the source of ROS, derived primarily from superoxide anions $\left(\mathrm{O}_{2}^{-\bullet}\right)$, via enzymatic reactions [8,9]. As part of the NOX family, seven oxidases (NOX1-5 and Duoxl-2) are recognized [10]. Of these, NOX4 can produce both superoxide anions $\left(\mathrm{O}_{2}{ }^{-\bullet}\right)$ as well as hydrogen peroxide $\left(\mathrm{H}_{2} \mathrm{O}_{2}\right)[11,12]$. Nitric oxide (NO) is produced by the sequential oxidation/reduction of L-arginine to L-citrulline by nitric oxide synthase (NOS), which exists in the form of inducible NOS (iNOS), neuronal NOS (nNOS), and endothelial NOS (eNOS) [13]. NO can react with superoxide anions $\left(\mathrm{O}_{2}{ }^{-\bullet}\right)$ 
and form peroxynitrite $\left(\mathrm{ONOO}^{-}\right)$which has a highly potent oxidizing and nitrosating ability [14]. This reaction prompts eNOS uncoupling, resulting in an increase in the formation of superoxide anions $\left(\mathrm{O}_{2}^{-\bullet}\right)$ [15]. Moreover, peroxynitrite $\left(\mathrm{ONOO}^{-}\right)$oxidizes the eNOS cofactor and further promotes eNOS uncoupling [16].

2.2. Cigarette Smoking. Cigarette smoke is known as one of the exogenous sources of ROS [17] and contains multiple ROS producers, such as nicotine and cadmium. Nicotine promotes nitric oxide (NO) production and increases proangiogenic factors [18] and cadmium accumulates preferentially in the RPE and choroid and increases ROS production [19]. Moreover, hydroquinone (HQ) is also included in cigarette smoke. HQ is an abundant oxidant in nature, found in processed foods, plastic containers, and atmospheric pollutants. In addition, cigarette smoke extract (CSE) has been shown to induce alterations to mitochondrial integrity, increase in lipid peroxidation, and significant human RPE cell death [20, 21].

Excess light exposure is also included as a source of ROS. The energy contained in a photon of light changes electron orbitals and can break bonds directly.

2.3. Light Exposure. Light exposure reduces lipofuscin autofluorescence [22]. Autofluorescence photobleaching is an indication of lipofuscin photooxidation [23]. At a higher level of light exposure, such as after prolonged exposure or being subjected to blue light, RPE disruption occurs in a manner which permanently alters the autofluorescence pattern [24]. Usually, autofluorescence photobleaching recovers after several hours; however, the detailed mechanism remains unclear. Excess light exposure induces cell death in a murine retinal cone cell line $(661 \mathrm{~W})$ and can cause a disruption in the phagocytotic function of a human retinal pigment epithelial cell line (ARPE-19) [25, 26].

Oxidative stress entails an excess amount of reactive oxygen species (ROS) that leads to oxidative damage to DNA, proteins, lipids, and mitochondria. Mitochondria become progressively more incompetent with age. Therefore, oxidative stress is associated with several age-related diseases. For a detailed summary of the factors affected by ROS, please see the review by Davalli et al. [27].

2.4. Endoplasmic Reticulum (ER) Stress. Oxidative stress is closely linked to endoplasmic reticulum (ER) stress [2831]. During the induction of the unfolded protein response (UPR), ROS are produced by protein disulfide isomerase (PDI), endoplasmic reticulum oxidoreductin (ERO-1), and NADPH oxidase complexes (i.e., NOX4) [32, 33]. ROS are produced during the transfer of electrons from protein thiol to molecular oxygen by ERO-1 and PDI and during protein misfolding due to the depletion of glutathione (GSH) [34]. In addition, after utilizing GSH, thiols interact again with ERO-1/PDI and are reoxidized. These chain reactions then generate further ROS [34]. ROS can also be produced by unfolded proteins independent of disulfide bond formation. Unfolded proteins in the ER can lead to $\mathrm{Ca}^{2+}$ release into the cytosol, which then increases ROS formation in mitochondria [35]. ATP depletion caused by protein folding and refolding processes in the ER lumen is also considered to contribute to increased ATP and ROS production by stimulating mitochondrial oxidative phosphorylation.

2.5. Inflammation. Oxidative stress is linked to inflammation [36-39]. It has been reported that oxidative stress-induced RPE cell death primarily due to necrosis induces the expression of an inflammatory gene, high mobility group protein $\mathrm{B} 1$ (HMGB1) [40]. Moreover, the inflammatory cytokine, tumor necrosis factor- (TNF-) $\alpha$, is also induced in macrophages and healthy RPE cells by the medium of dying cells exposed to oxidative stress [41]. Conversely, proinflammatory cytokines, such as TNF- $\alpha$, interleukin-1 $\beta$ (IL-1 $\beta$ ), or interferon- $\gamma$ (IFN$\gamma$ ), induce intracellular and extracellular ROS production in human RPE cells [42]. Indeed, these proinflammatory cytokines are upregulated in the eyes of patients with glaucoma, age-related macular degeneration, diabetic retinopathy, or retinal vein occlusion [43-46].

In particular, endothelial cells are affected by inflammation. Inflammation induces shifts in the endothelial cell phenotype, increasing the expression of inflammatory mediators, cytokines, and iNOS activation [47]. These events are observed in both RPE cells and endothelial cells. Moreover, RPE interacts with endothelial cells (ECs) directly and can enhance the proangiogenic potential of the ECs, such as proliferation and migration. For example, TNF- $\alpha$ upregulates the expression of vascular endothelial growth factor (VEGF), a major angiogenic factor, in RPE cells via the ROS-dependent activation of $\beta$-catenin [48]. ROS also affects VEGF-stimulated VEGF receptor 2 dimerization and autophosphorylation. Conversely, VEGF further stimulates ROS production through the activation of NOX in endothelial cells [49]. It has been reported that hypoxia-induced microRNA-424 (miR-424), a member of the miR-16 family crucial for the regulation of cell differentiation [50, 51], promotes hypoxia-inducible factor- (HIF-) $1 \alpha$ stability in human umbilical vein endothelial cells (HUVECs). This is achieved by inhibiting the expression of a scaffolding protein, Cullin-2, which is essential for the assembly of the HIF E3 ubiquitin ligase complex [52]. ROS also inhibits the activity of prolyl hydroxylase enzymes (PHD) and factor-inhibiting HIF-1 $\alpha$ (FIH) by reducing $\mathrm{Fe}^{2+}$ availability [53]. In addition, endothelial cell apoptosis is triggered by high glucoseinduced overexpression of iNOS in RPE cells activating the PKR-like endoplasmic reticulum kinase (PERK) pathway [54].

2.6. Nuclear Factor-Erythroid 2-Related Factor 2 (Nrf2). Nuclear factor-erythroid 2-related factor $2(\mathrm{Nrf} 2)$ is a nuclear transcription factor regulating antioxidant defense. Nrf2 usually exists in the cytosol and interacts with Kelch-like ECH-associated protein 1 (Keap1), an adaptor for a Cullin-3(Cul3-) based ubiquitin ligase [55]. Under normal condition, the amount of Nrf2 is maintained at lower levels than that of Keapl and Cul3 proteins. However, under oxidative stress condition, electrophilic agent increases Nrf2 much more than Keapl and Cul3 proteins, resulting in the accumulation of Nrf2 in the nucleus. In contrast, Keap1 and Cul3 are not changed in their abundance, subcellular localization, 


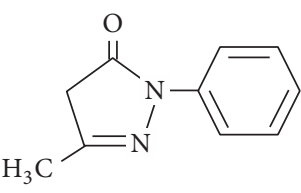

Edaravone

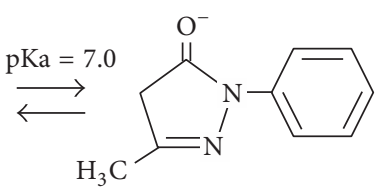

Edaravone anion

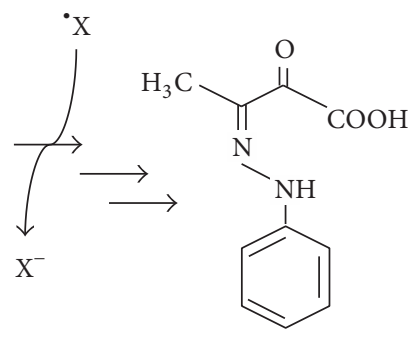

$\mathrm{OPB}$

FIGURE 1: A hypothetical radical-scavenging mechanism of edaravone. Edaravone anion scavenges radicals ( $\mathrm{X})$ to produce anion bodies $\left(\mathrm{X}^{-}\right)$ and edaravone radicals. The final product is 2-oxo-3-(phenylhydrazono)-butanoic acid (OPB), which is without oxidation power.

and interaction in response to electrophilic stimuli [56]. The increased Nrf2 translocates into the nucleus, dimerizes with Maf proteins, and binds to the antioxidant/electrophile response element (ARE/EpRE) in the promoters of its target genes. These genes encode protective proteins against oxidative stress, including superoxide dismutase (SOD), catalase, glutathione S-transferases (GST), NADPH quinine oxidoreductase (NQO-1), peroxiredoxin (PRX), heme oxygenase1 (HO-1), and thioredoxin reductase-1 (TXNRD1) [57-59]. Catalase and SOD directly neutralize hydrogen peroxide $\left(\mathrm{H}_{2} \mathrm{O}_{2}\right)$ and superoxide anion $\left(\mathrm{O}_{2}{ }^{-\bullet}\right)$, respectively [60, 61]. GST and NQO-1 function as a detoxicating enzyme of electrophilic substances and a xenobiotic-metabolizing enzyme, respectively $[62,63]$. HO-1 removes toxic heme, producing iron ions $\left(\mathrm{Fe}^{2+}\right)$, carbon monoxide (CO), and biliverdin [64]. Both biliverdin and its reductive form, bilirubin, are potent antioxidants; bilirubin breaks the oxidation chain reaction of polyunsaturated fatty acids [65].

\section{Edaravone}

Oxidative stress is highly complex and is linked to other forms of stress and effects on various cells. There are two strategies for reducing oxidative stress: (1) enhancing antioxidant enzymes and (2) reducing ROS directly.

Edaravone (3-methyl-1-phenyl-2-pyrazolin-5-one, MCI186 , Radicut $\left.{ }^{\circledR}\right)$ is a free radical scavenger and a drug used to treat acute ischemic stroke [66]. In Japan, edaravone is administered via an intravenous infusion within $24 \mathrm{~h}$ of the onset of acute ischemic stroke in patients with lacunae, largeartery atherosclerosis, and cardioembolic stroke.

The hypothetical reaction mechanism of edaravone involves the electron donation to free radicals. The final product derived from edaravone is 2-oxo-3-(phenylhydrazono)butanoic acid which is without oxidation power (Figure 1) [67-70]. The main metabolites consist of sulfoconjugate and glucuronic acid conjugation. Edaravone quenches hydroxy radicals $\left({ }^{\circ} \mathrm{OH}\right)$ and inhibits lipid peroxidation dependent and independent of hydroxy radicals $\left({ }^{\circ} \mathrm{OH}\right)[67,71,72]$. Indeed, we demonstrated that edaravone scavenged the intracellular not only hydroxy radicals $\left({ }^{\circ} \mathrm{OH}\right)$ but also superoxide anion $\left(\mathrm{O}_{2}{ }^{-\bullet}\right)$ and hydrogen peroxide $\left(\mathrm{H}_{2} \mathrm{O}_{2}\right)$ [73]. Moreover, edaravone shows a neuroprotective effect against ischemia/reperfusion brain injury and cardiopulmonary resuscitation through a $\mathrm{Bax} / \mathrm{Bcl}-2$ dependent antiapoptotic mechanism [74, 75]. Edaravone also ameliorates photoreceptor cell death after experimental retinal detachment through increasing the level of the antiapoptotic Bcl-2 [76].

Edaravone has not only antiapoptotic effect but also anti-inflammatory effect. In the brain with the treatment of middle cerebral artery occlusion, the expression levels of proinflammatory cytokines such as tumor necrosis factoralpha (TNF- $\alpha$ ), interleukin-1 beta (IL-1 $\beta$ ), and inducible nitric oxide synthase (iNOS) were effectively suppressed by edaravone [77]. In addition, the expressions of the inflammatory cytokines TNF- $\alpha$ and monocyte chemoattractant protein-1 (MCP-1) in retinal lysates were significantly reduced by edaravone treatment [76].

Edaravone is a low-molecular-weight agent and exerts potency both in water and under lipid soluble conditions [67]. Thus, edaravone is a free radical scavenger with properties of both of vitamins $\mathrm{C}$ and $\mathrm{E}$. In addition, edaravone readily crosses the blood-brain barrier, which is unlike other free radical scavengers. These properties of edaravone may be important for its neurovascular protective effects observed in patients with acute ischemic stroke.

Previously, our laboratory demonstrated that combination therapy with normobaric hyperoxia and plus edaravone prevented neuronal damage following focal cerebral ischemia and reperfusion in mice [78]. For a summary of multiple reports on the protective effects of edaravone, please refer to the review by Watanabe et al. [79].

This review describes the relationship between oxidative stress and retinal disease, as well as the effect of edaravone against retinal disease.

\section{Age-Related Macular Degeneration (AMD)}

4.1. Pathogenesis and Pharmacological Therapy. Age-related macular degeneration (AMD) is the leading cause of blindness in elderly individuals throughout the world, and approximately 50 million people suffer from AMD worldwide [80]. In addition, the number of patients with AMD continues to increase, and it is estimated that approximately 198 million people currently suffer from AMD [81]. AMD is classified into two types: "dry" and "wet." In the dry-type AMD, gradual vision loss and drusen, the yellow deposits located under the retina, are diagnostic features [82]. Lipofuscin is the main constituent of drusen and is produced during the reaction of cell metabolites, such as lipid peroxidation [83, 84]. 
Lipofuscin is deposited when the production of lipofuscin is beyond the disposal capacity of the photoreceptor pigment in RPE [85]. RPE is particularly susceptible to ROS formation due to its high consumption of oxygen, high proportion of polyunsaturated fatty acids, and constant exposure to light. Drusen causes retinal pigment epithelium (RPE) degeneration and "geographic atrophy" appears as feature in eye fundus. When it spreads to the fovea, rapid and severe vision loss occurs. Some dry-type AMD pathology advances to wettype AMD pathology. The wet-type AMD accounts for 10$15 \%$ of AMD patients, and choroidal neovascularization is characterized. The vessels within Bruch's membrane or the sub-RPE space are very weak; therefore, hemorrhage and/or vascular leakage cause damage to the retina leading to further vision loss.

There are several events that occur during the development of AMD, such as oxidative stress, the formation of drusen and RPE dysfunction, apoptosis, activating immune system, senescent loss of homeostatic control, and Bruch's membrane abnormalities. These events are highly complex and involve crosstalk, as well as interaction with each other. As the name indicates, AMD is major ocular disease in elderly individuals [80]. With aging, antioxidant level declines and ROS level increases, ensuring oxidative stress [86]. By aging, macular carotenoids level [87], glutathione S-transferase-1 expression level [88], and vitamin E level [89] are decreased and lipid peroxidation is increased [90]. In contrast, lipofuscin $[91,92]$, mitochondrial DNA damage in retina $[93,94]$, advanced lipid peroxidation, and glycation end products [90, 95] are increased. Aging changes the homeostasis of these factors, which means that the rate of AMD development is high in elderly individuals.

Currently, there is no treatment available for the drytype AMD. In the Age-Related Eye Disease Study (AREDS), antioxidant micronutrients, including $\beta$-carotene, vitamin $C$, vitamin E, and zinc, showed a suppressive effect on disease progression [96]. As a therapeutic drug for wet-type AMD, the anti-VEGF antibody is commonly used. AntiVEGF antibody treatment is the current standard therapy that improves the visual function in patients with wettype AMD [97]. Patients receive the anti-VEGF antibody treatment via an intravitreal injection at regular intervals. An intravitreal injection is the most common and widely recommended route of drug administration to treat posterior ocular diseases [98]. However, this method is highly invasive and is associated with the risk of infection (0.02 to 1.6\%) [99103]. In addition, the anti-VEGF antibody is very expensive, and the financial burden on patients with the wet type of AMD is extremely high. Therefore, the development of novel therapeutic drug is an urgent need.

4.2. The Effects of Edaravone. We demonstrated that edaravone is effective against retinal degeneration both in vivo and in vitro [104-106]. A model of light-induced retinal degeneration in mice is commonly used for the evaluation of retinal damage and photoreceptor cell death induced by excess exposure to light [107-109]. Previously, we demonstrated that oxidative stress was involved in light-induced photoreceptor cell death [110-113]. An electroretinogram
(ERG) revealed that the intraperitoneal administration of edaravone at a dose of $3 \mathrm{mg} / \mathrm{kg}$ (30 min before and just after light exposure) inhibited visual dysfunction five days after light exposure [104]. Moreover, it decreased the number of apoptotic TUNEL-positive cells and was a marker of oxidative damage to DNA, 8-hydroxy-2-deoxyguanosine- (8OHdG-) positive cells, and the expression of phosphorylated JNK and phosphorylated p38, but not that of phosphorylated ERK, in the whole retina after light exposure [104]. These data suggest that oxidative stress is involved in light-induced retinal degeneration, and the systemic administration of edaravone may slow the progression of photoreceptor degeneration through antioxidative stress [73] and antiapoptotic effects [74-76] (Figure 2). Moreover, this protective effect of edaravone was also observed in N-methyl-N-nitrosourea(NMU-) induced retinal photoreceptor degeneration in mice, a model of retinitis pigmentosa [114].

Next, we evaluated the effect of the edaravone eye drop, consisting of edaravone-loaded submicron-sized liposomes (ssLips). Eye drop administration is a noninvasive and simple method of the delivery for patients. The protective effects against visual dysfunction and apoptosis induced by light exposure were shown by edaravone-loaded ssLips at a dose that free edaravone could not prevent [105]. Moreover, the edaravone-loaded ssLips used in the study exhibited a low toxicity in ocular cell lines [105].

Edaravone also demonstrated its effectiveness in the wettype AMD model. A laser-induced choroidal neovascularization $(\mathrm{CNV})$ model was developed as an animal model of wettype AMD [115]. Laser photocoagulation ruptures Bruch's membrane and induces $\mathrm{CNV}$, which is the main characteristic feature of the disease [116]. Edaravone administered intraperitoneally or intravenously reduced the CNV area and vascular leakage [106]. Surprisingly, edaravone administered intravenously within $24 \mathrm{~h}$ after photocoagulation also demonstrated an inhibitory effect [106]. The mechanism of the effect mediated by edaravone is via the reduction of ROS, lipid peroxidation, and VEGF-induced endothelial cell proliferation. Moreover, edaravone was also found to reduce the laser-induced CNV area in the common marmoset, a small monkey [106]. Edaravone demonstrated effectiveness against experimental laser-induced CNV in both rodents, as well as primates, indicating that it may be effective against wet-type AMD characterized by CNV (Figure 3).

Edaravone is already approved for the treatment of acute ischemic stroke. This means that feasibility of clinical application is high because its effectivity and tolerability are very clear. If a combination therapy of anti-VEGF antibody and edaravone exerts a great inhibitory effect against CNV, edaravone would be a powerful candidate for AMD therapeutic medicine and could extend the period of intravitreal injection.

\section{Glaucoma}

5.1. Pathogenesis and Pharmacological Therapy. Glaucoma is an optic neuropathy, characterized by retinal ganglion cell (RGC) death, optic nerve head cupping, and visual dysfunction (e.g., scotoma) $[117,118]$. Glaucoma is the second 


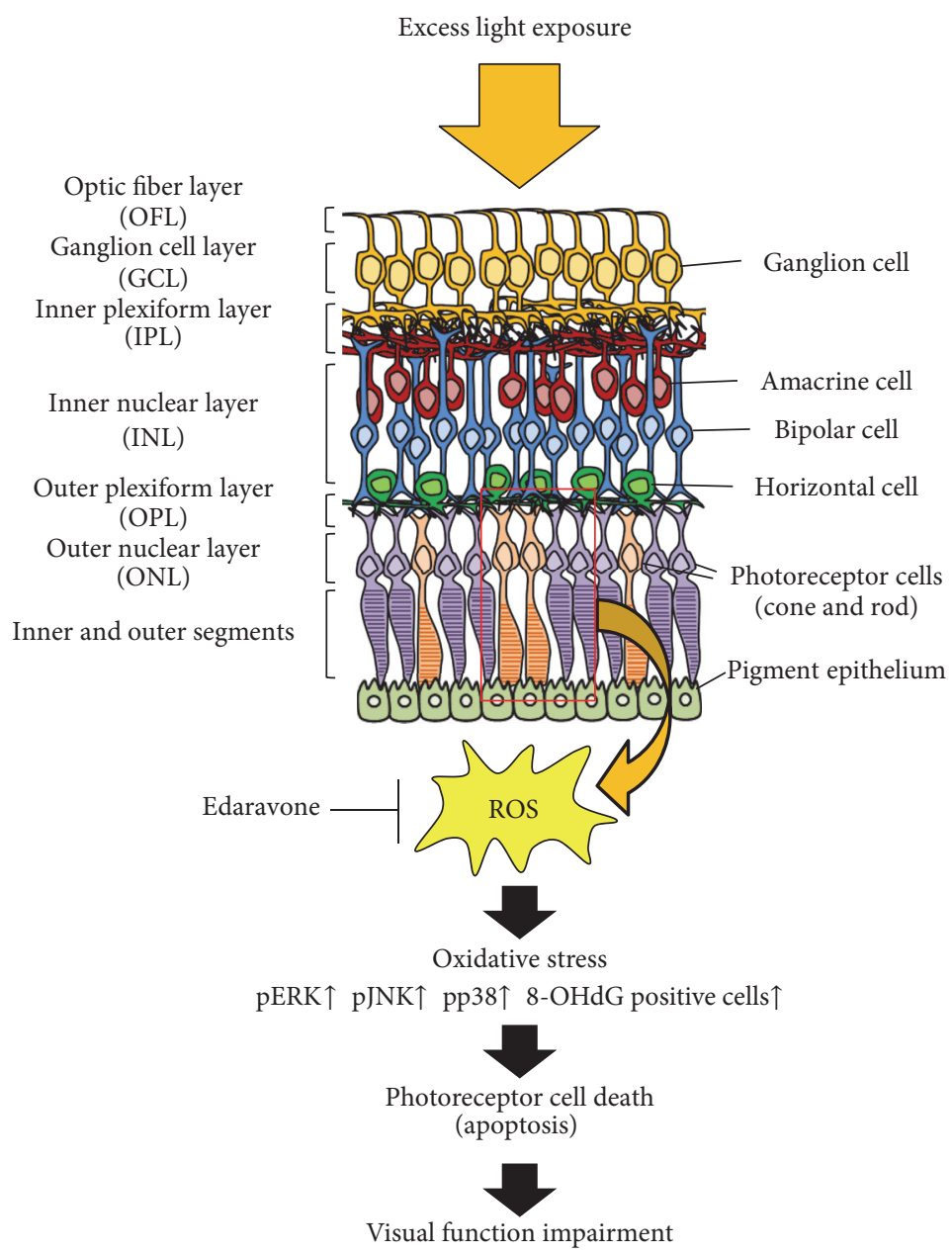

FIGURE 2: Protective effects of edaravone against light-induced retinal damage. Edaravone scavenges light-induced ROS and rescues lightinduced photoreceptor cell death by inhibiting phosphorylated JNK, p38 (but not ERK), and oxidative stress to DNA.

most common cause of blindness worldwide [119], and it is expected that over 80 million people will suffer from glaucoma by 2020 [119]. High intraocular pressure (IOP) was considered as a major cause of developing glaucoma; however, in some cases, RGC loss occurred despite a lower IOP [120]. Therefore, IOP reduction alone may be not sufficient for the treatment of glaucoma.

The axons of the RGCs located within the inner retina constitute the retinal nerve fiber layer (RFNL) and merge to form the optic nerve. Therefore, RGC loss causes a loss of RFNL thickness and optic nerve head cupping [118]. The mechanism of RGC loss remains unknown. Similar to agerelated macular degeneration, glaucoma is also associated with oxidative stress [121-123]. Previously, our laboratory demonstrated that antioxidant agents including Coenzyme Q10, Astaxanthin, Zeaxanthin, and Docosahexaenoic acid inhibited RGC death induced by $\mathrm{H}_{2} \mathrm{O}_{2}$ or the glutamate analog, N-methyl-D-aspartate (NMDA) [124-127]. In a preclinical study, it was revealed that excitatory amino acids (e.g., glutamate and glycine) were increased and that oxidative stress was one of risk factors for RGC death [128-130]. Moreover, oxidative stress leads to the early impairment of trabecular meshwork (TM) cells which are responsible for aqueous humor outflow and further elevation of the IOP $[123,131]$. Indeed, multiple reports have shown that, in the aqueous humor of patients with glaucoma, there were lower levels of antioxidants and elevated markers of oxidative stress [132-134].

In preclinical studies, glutamate antagonists, neurotrophic factors, antioxidants, calcium channel blockers, brimonidine, and nitric oxide synthase inhibitors were shown to exhibit the neuroprotective effects [124, 135-143]. A few agents (e.g., brimonidine and memantine) were evaluated in clinical trials. However, these data have not been conclusive $[144,145]$.

5.2. The Effects of Edaravone. In the model of glaucoma, NMDA-induced retinal damage in mice is commonly used. NMDA induces calcium entry and ROS production, such as $\mathrm{NO}$ and superoxide anions $\left(\mathrm{O}_{2}{ }^{-\bullet}\right)$, and results in RGC death $[146,147]$.

Edaravone in the form of 5 and $50 \mathrm{nmol}$ intravitreous injections or 1 and $3 \mathrm{mg} / \mathrm{kg}$ intravenous injections significantly protected against the NMDA-induced reduction of retinal thickness [73]. Moreover, a $50 \mathrm{nmol}$ intravitreous injection of edaravone decreased the retinal expression of 


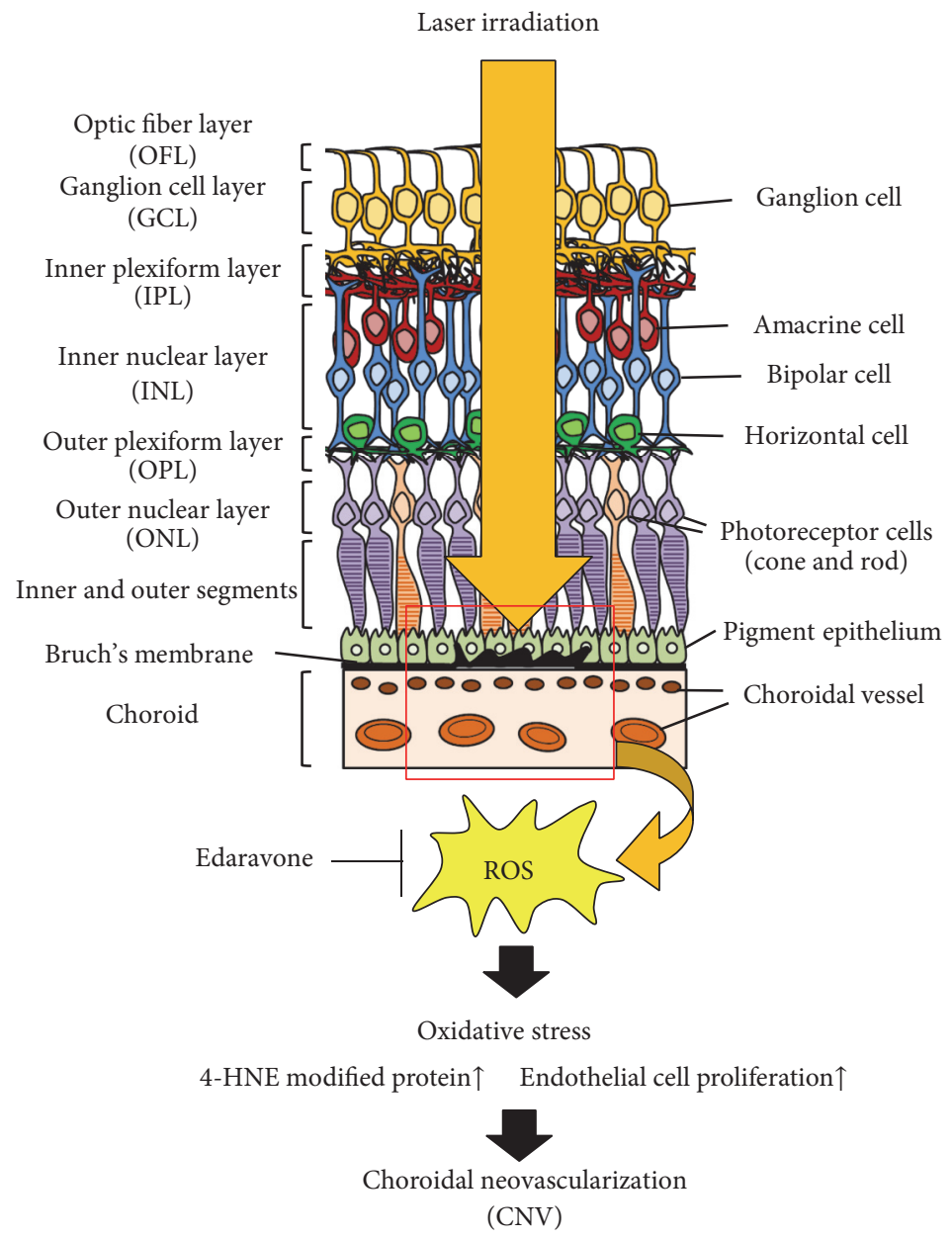

FIGURE 3: Protective effects of edaravone against laser-induced choroidal neovascularization. Edaravone scavenges laser-induced ROS and rescues laser-induced choroidal neovascularization by inhibiting lipid peroxidation and endothelial cell proliferation.

TUNEL-positive cells, markers of oxidative stress (4-HNE and $8-\mathrm{OHdG}$ ), and phosphorylated JNK and p38 but not that of phosphorylated ERK (Figure 4) [73]. Another study reported that an intraperitoneal injection of edaravone at a dose of $3 \mathrm{mg} / \mathrm{kg}$ also showed potent neuroprotective activity in a hyaluronic acid-induced glaucoma model [148]. Moreover, edaravone-loaded liposomes suppressed the NMDAinduced reduction of retinal thickness [149]. Elevated IOP induces transient ischemic injury. Edaravone also decreased retinal ganglion cell death induced by oxygen-glucose deprivation (OGD) stress in an ischemia-reperfusion injury model in vitro [73].

\section{Diabetic Retinopathy (DR)}

6.1. Pathogenesis and Pharmacological Therapy. Oxidative stress is also associated with diabetic retinopathy (DR) $[150,151]$. Diabetic retinopathy is one of the most common complications of diabetes mellitus (DM) and the leading cause of blindness and visual dysfunction in working-age populations. Similar to AMD, the number of patients with DM and DR is increasing globally. In the United States alone, 4.1 million people have DR, and the number of patients is expected to double by 2025 [152].
Hyperglycemia induces the excess production of mitochondrial ROS. Increased ROS activates the poly-ADP-ribose polymerase (PARP) pathway and decreases glyceraldehydes 3-phosphate dehydrogenase (GAPDH) activity, which leads to the further activation of the polyol pathway, the protein kinase $\mathrm{C}(\mathrm{PKC})$ pathway, advanced glycation end products (AGEs) pathway, and the hexosamine pathway [151, 153, 154]. Under chronic oxidative stress conditions induced by hyperglycemia, Sirtl and Sirt6 are downregulated and result in endothelial cell senescence $[155,156]$. Moreover, increased retinal ROS stabilizes hypoxia-inducible factor- $1 \alpha$ (HIF- $1 \alpha$ ) and leads to the upregulation of angiogenic genes (e.g., VEGF). As a result, pathological angiogenesis is induced [157-160]. Indeed, the concentration of VEGF was found to be upregulated in the vitreous humor of patients with proliferative diabetic retinopathy, compared to the controls with a macular hole [161]. These pathological vessels can result in a hemorrhage or vascular leakage due to its weakness; therefore, such events cause macular edema, retinal ischemia, and retinal detachment. Furthermore, hyperglycemia accelerates premature endothelial cell apoptosis via mitochondrial dysfunction [162].

Increased hyperglycemia-induced ROS affects both endothelial cells, as well as neuronal cells [163]. Increased 


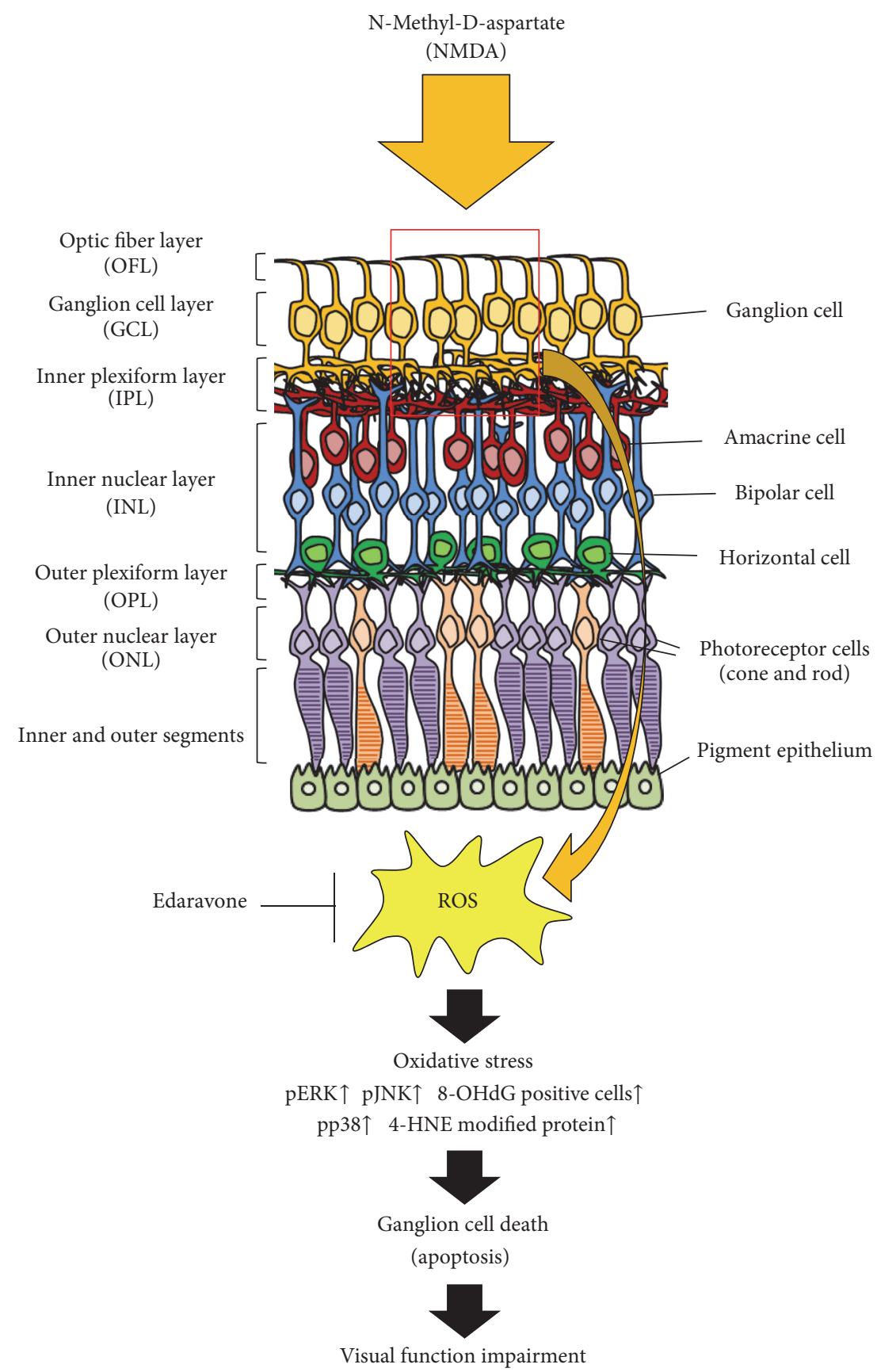

FIGURE 4: Protective effects of edaravone against NMDA-induced retinal damage. Edaravone scavenges NMDA-induced ROS and rescues NMDA-induced retinal ganglion cell death by inhibiting phosphorylated JNK, p38 (but not ERK), lipid peroxidation, and oxidative stress to DNA.

ROS also decreases brain-derived neurotrophic factor (BDNF) that regulates axonal growth, synaptic activity, and neuronal survival. The damage to the synaptic transmitter and degradation of neurotrophic factors causes neuronal cell apoptosis and visual impairment [164].

Laser panretinal photocoagulation (PRP) is the primary mode of therapy for neovascularization in proliferative diabetic retinopathy (PDR). PRP treatment was proven to decrease the frequency of severe visual loss in PDR with high-risk characteristics ( $>50 \%$ decrease) [165]. Later, Early
Treatment Diabetic Retinopathy Study (ETDRS) demonstrated that the frequency of severe visual loss in severe nonproliferative DR (NPDR) and early PDR was decreased by PRP [166]. However, in mild or moderate NPDR, adverse effects of PRP on visual acuity and visual field were also observed [166]. Therefore, for eyes with macular edema, focal photocoagulation is effective in reducing the risk of moderate visual loss. In recent years, anti-VEGF antibody has received a lot of attention. Ranibizumab (Lucentis ${ }^{\circledR}$ ) monotherapy provided better visual outcome than standard 
focal laser in patients with diabetic macular edema (DME) [167]. Moreover, aflibercept (Eylea ${ }^{\circledR}$ ) also provided better visual outcome than standard focal laser in patients with DME [168] and was more effective in improving vision than ranibizumab at worse levels of initial visual acuity [169].

6.2. The Effects of Edaravone. The injection of streptozotocin (STZ) is commonly used for the model of type 1 DM. In this model, retinal damage and visual impairment are observed. An intraperitoneal injection of edaravone at a dose of $3 \mathrm{mg} / \mathrm{kg}$ was found to significantly attenuate diabetes-induced RGCs death, the upregulation of ROS, ERK1/2 phosphorylation, cleaved caspase-3, and the downregulation of BDNF [170]. These data suggest that oxidative stress is highly involved in diabetic retinal damage and that the systemic administration of edaravone may slow the progression of retinal neuropathy induced by diabetes.

\section{Branch Retinal Vein Occlusion (BRVO)}

7.1. Pathogenesis and Pharmacological Therapy. RGC death also occurs under the retinal ischemic conditions during which ROS production is active. Studies have shown that hydroxyl radical $\left({ }^{\circ} \mathrm{OH}\right)$ was generated in the retina during ischemic conditions and remained elevated during the reperfusion period [171, 172]. Retinal vein occlusion includes both a branch retinal vein occlusion (BRVO) and central retinal vein occlusion (CRVO). In the United States, it is estimated that approximately 100,000 people suffer from RVO.

Similar to DR, the condition including macular edema, retinal ischemia, and fundus hemorrhage is observed. Retinal ischemia impairs the integrity of the blood retinal barrier, and RVO is a common complication of DR. Blood hyperviscosity is also observed in RVO pathology. In determining blood viscosity, erythrocyte deformability plays a critical role. In RVO patients, ROS production and membrane lipid peroxidation, which are indicative of erythrocyte oxidative stress, are observed and positively correlated with erythrocyte membrane viscosity and deformities [173]. A study in young adult CRVO patients revealed that the serum levels of an antioxidant factor, paraoxonase-1 arylesterase (PON1-ARE) activity, were negatively correlated with hyperhomocysteinemia and lipid peroxidation [174]. Moreover, a glucose-6phosphate dehydrogenase (G6PD) deficiency was associated with increased erythrocyte vulnerability to oxidative stress and developed CRVO [175]. Clinically, antiphospholipid antibodies have been associated with the development of RVO, since it induces oxidative stress in endothelial cells [176].

Anti-VEGF treatment is applied as the therapy for RVO. An intravitreal injection of triamcinolone acetonide is also applied due to the low cost and longer half-life. However, the effects are not permanent, and there are some risks for the development of adverse events, such as cataract formation and elevated IOP [177].

7.2. The Effects of Edaravone. We have reported that the intraperitoneal administration of edaravone at a dose of $1 \mathrm{mg} / \mathrm{kg}$ significantly decreased the reduction of retinal thickness and TUNEL-positive cells induced by the ligation of the pterygopalatine artery (PPA) and the external carotid artery (ECA), in a murine retinal ischemic model [178]. Moreover, the intraperitoneal administration of edaravone at a dose of $3 \mathrm{mg} / \mathrm{kg}$ lowered a marker of lipid peroxidation, malondialdehyde (MDA), and enhanced superoxide dismutase (SOD) in rodent retinal tissue [179]. MDA is a product of lipid peroxidation and exhibits cytotoxicity. SOD is an antioxidant enzyme that neutralizes superoxide anions $\left(\mathrm{O}_{2}{ }^{-\bullet}\right)$. In addition, edaravone inhibited the retinal ischemia/reperfusioninduced visual dysfunction and apoptosis of retinal neurons within the inner nuclear, ganglion cell, and outer nuclear layers [179]. These data suggest that edaravone scavenges ROS, thereby reducing lipid oxidation, increasing the activity of antioxidant enzyme, and decreasing the extent of cell death and retinal thickness.

In a clinical trial, edaravone following arteriovenous sheathotomy was effective against macular edema associated with a branch retinal vein occlusion (BRVO) and improved the best-corrected visual acuity [180].

\section{Conclusions}

Oxidative stress is highly complex and connected to other factors, such as ER stress and inflammation. Moreover, in retinal diseases, including age-related macular degeneration (AMD), glaucoma, diabetic retinopathy (DR), and retinal vein occlusion (RVO), oxidative stress plays pivotal roles in the development and acceleration of these diseases. In the treatment of these ocular diseases, a therapeutic strategy which targets oxidative stress may be effective.

Edaravone demonstrates protective effects against AMD, glaucoma, DR, and RVO models, suggesting that edaravone may be promising as a novel therapeutic drug candidate.

\section{Competing Interests}

The authors declare that they have no competing interests.

\section{References}

[1] J. Li, O. Wuliji, W. Li, Z.-G. Jiang, and H. A. Ghanbari, "Oxidative stress and neurodegenerative disorders," International Journal of Molecular Sciences, vol. 14, no. 12, pp. 2443824475, 2013.

[2] E. Niedzielska, I. Smaga, M. Gawlik et al., "Oxidative stress in neurodegenerative diseases," Molecular Neurobiology, vol. 53, no. 6, pp. 4094-4125, 2016.

[3] D. L. Williams, "Oxidative stress and the eye," Veterinary Clinics of North America: Small Animal Practice, vol. 38, no. 1, pp. 179192, 2008.

[4] M. Barot, M. R. Gokulgandhi, and A. K. Mitra, "Mitochondrial dysfunction in retinal diseases," Current Eye Research, vol. 36, no. 12, pp. 1069-1077, 2011.

[5] A.-S. Kiang, M. M. Humphries, M. Campbell, and P. Humphries, "Antioxidant therapy for retinal disease," in Retinal Degenerative Diseases: Mechanisms and Experimental Therapy, D. J. Ash, C. Grimm, G. J. Hollyfield, E. R. Anderson, M. M. LaVail, and C. Bowes Rickman, Eds., pp. 783-789, Springer, New York, NY, USA, 2014. 
[6] R. V. Lloyd, P. M. Hanna, and R. P. Mason, "The origin of the hydroxyl radical oxygen in the Fenton reaction," Free Radical Biology and Medicine, vol. 22, no. 5, pp. 885-888, 1997.

[7] D. X. Zhang and D. D. Gutterman, "Mitochondrial reactive oxygen species-mediated signaling in endothelial cells," American Journal of Physiology-Heart and Circulatory Physiology, vol. 292, no. 5, pp. H2023-H2031, 2007.

[8] B. M. Babior, "NADPH oxidase," Current Opinion in Immunology, vol. 16, no. 1, pp. 42-47, 2004.

[9] M. Ushio-Fukai, "VEGF signaling through NADPH oxidasederived ROS," Antioxidants \& Redox Signaling, vol. 9, no. 6, pp. 731-739, 2007.

[10] S. A. Jones, V. B. O’Donnell, J. D. Wood, J. P. Broughton, E. J. Hughes, and O. T. G. Jones, "Expression of phagocyte NADPH oxidase components in human endothelial cells," The American Journal of Physiology-Heart and Circulatory Physiology, vol. 271, no. 4, pp. H1626-H1634, 1996.

[11] J. D. Lambeth, T. Kawahara, and B. Diebold, "Regulation of Nox and Duox enzymatic activity and expression," Free Radical Biology \& Medicine, vol. 43, no. 3, pp. 319-331, 2007.

[12] T. Ago, T. Kitazono, H. Ooboshi et al., "Nox4 as the major catalytic component of an endothelial NAD(P)H oxidase," Circulation, vol. 109, no. 2, pp. 227-233, 2004.

[13] U. Förstermann and W. C. Sessa, "Nitric oxide synthases: regulation and function," European Heart Journal, vol. 33, no. 7, pp. 829-837, 2012.

[14] P. Pacher, J. S. Beckman, and L. Liaudet, "Nitric oxide and peroxynitrite in health and disease," Physiological Reviews, vol. 87, no. 1, pp. 315-424, 2007.

[15] J. B. Laursen, M. Somers, S. Kurz et al., "Endothelial regulation of vasomotion in ApoE-deficient mice: implications for interactions between peroxynitrite and tetrahydrobiopterin," Circulation, vol. 103, no. 9, pp. 1282-1288, 2001.

[16] W. Chen, L. J. Druhan, C.-A. Chen et al., "Peroxynitrite induces destruction of the tetrahydrobiopterin and heme in endothelial nitric oxide synthase: transition from reversible to irreversible enzyme inhibition," Biochemistry, vol. 49, no. 14, pp. 3129-3137, 2010.

[17] D. F. Church and W. A. Pryor, "Free-radical chemistry of cigarette smoke and its toxicological implications," Environmental Health Perspectives, vol. 64, pp. 111-126, 1985.

[18] M. Pons and M. E. Marin-Castaño, "Nicotine increases the VEGF/PEDF ratio in retinal pigment epithelium: a possible mechanism for CNV in passive smokers with AMD," Investigative Ophthalmology \& Visual Science, vol. 52, no. 6, pp. 38423853, 2011.

[19] N. K. Wills, V. M. S. Ramanujam, J. Chang et al., "Cadmium accumulation in the human retina: effects of age, gender, and cellular toxicity," Experimental Eye Research, vol. 86, no. 1, pp. 41-51, 2008.

[20] P. J. Deisinger, T. S. Hill, and J. C. English, "Human exposure to naturally occurring hydroquinone," Journal of Toxicology and Environmental Health, vol. 47, no. 1, pp. 31-46, 1996.

[21] A. P. DeCaprio, "The toxicology of hydroquinone-relevance to occupational and environmental exposure," Critical Reviews in Toxicology, vol. 29, no. 3, pp. 283-330, 1999.

[22] J. I. W. Morgan, J. J. Hunter, W. H. Merigan, and D. R. Williams, "The reduction of retinal autofluorescence caused by light exposure," Investigative Ophthalmology \& Visual Science, vol. 50, no. 12, pp. 6015-6022, 2009.
[23] J. J. Hunter, J. I. W. Morgan, W. H. Merigan, D. H. Sliney, J. R. Sparrow, and D. R. Williams, "The susceptibility of the retina to photochemical damage from visible light," Progress in Retinal and Eye Research, vol. 31, no. 1, pp. 28-42, 2012.

[24] B. J. Putting, R. C. V. J. Zweypfenning, G. F. J. M. Vrensen, J. A. Oosterhuis, and J. A. van Best, "Blood-retinal barrier dysfunction at the pigment epithelium induced by blue light," Investigative Ophthalmology \& Visual Science, vol. 33, no. 12, pp. 3385-3393, 1992.

[25] K. Tsuruma, Y. Tanaka, M. Shimazawa, Y. Mashima, and H. Hara, "Unoprostone reduces oxidative stress- and light-induced retinal cell death, and phagocytotic dysfunction, by activating BK channels," Molecular Vision, vol. 17, pp. 3556-3565, 2011.

[26] K. Tsuruma, Y. Nishimura, S. Kishi, M. Shimazawa, T. Tanaka, and H. Hara, "SEMA4A mutations lead to susceptibility to light irradiation, oxidative stress, and ER stress in retinal pigment epithelial cells," Investigative Ophthalmology and Visual Science, vol. 53, no. 10, pp. 6729-6737, 2012.

[27] P. Davalli, T. Mitic, A. Caporali, A. Lauriola, and D. D’Arca, "ROS, cell senescence, and novel molecular mechanisms in aging and age-related diseases," Oxidative Medicine and Cellular Longevity, vol. 2016, Article ID 3565127, 18 pages, 2016.

[28] B. Bhandary, A. Marahatta, H.-R. Kim, and H.-J. Chae, "An involvement of oxidative stress in endoplasmic reticulum stress and its associated diseases," International Journal of Molecular Sciences, vol. 14, no. 1, pp. 434-456, 2013.

[29] M. Yamauchi, K. Tsuruma, S. Imai et al., "Crocetin prevents retinal degeneration induced by oxidative and endoplasmic reticulum stresses via inhibition of caspase activity," European Journal of Pharmacology, vol. 650, no. 1, pp. 110-119, 2011.

[30] R. Uchibayashi, K. Tsuruma, Y. Inokuchi, M. Shimazawa, and H. Hara, "Involvement of Bid and caspase-2 in endoplasmic reticulum stress- and oxidative stress-induced retinal ganglion cell death," Journal of Neuroscience Research, vol. 89, no. 11, pp. 1783-1794, 2011.

[31] T. Adachi, H. Yasuda, S. Nakamura et al., "Endoplasmic reticulum stress induces retinal endothelial permeability of extracellular-superoxide dismutase," Free Radical Research, vol. 45, no. 9, pp. 1083-1092, 2011.

[32] J. D. Malhotra and R. J. Kaufman, "Endoplasmic reticulum stress and oxidative stress: a vicious cycle or a double-edged sword?" Antioxidants \& Redox Signaling, vol. 9, no. 12, pp. 22772293, 2007.

[33] S. B. Cullinan and J. A. Diehl, "PERK-dependent activation of Nrf2 contributes to redox homeostasis and cell survival following endoplasmic reticulum stress," The Journal of Biological Chemistry, vol. 279, no. 19, pp. 20108-20117, 2004.

[34] A. Higa and E. Chevet, "Redox signaling loops in the unfolded protein response," Cellular Signalling, vol. 24, no. 8, pp. 1548$1555,2012$.

[35] I. Moserova and J. Kralova, "Role of er stress response in photodynamic therapy: ROS generated in different subcellular compartments trigger diverse cell death pathways," PLoS ONE, vol. 7, no. 3, Article ID e32972, 2012.

[36] S. K. Biswas, "Does the interdependence between oxidative stress and inflammation explain the antioxidant paradox?" Oxidative Medicine and Cellular Longevity, vol. 2016, Article ID 5698931, 9 pages, 2016.

[37] S. Reuter, S. C. Gupta, M. M. Chaturvedi, and B. B. Aggarwal, "Oxidative stress, inflammation, and cancer: how are they linked?” Free Radical Biology and Medicine, vol. 49, no. 11, pp. 1603-1616, 2010. 
[38] R. Gill, A. Tsung, and T. Billiar, "Linking oxidative stress to inflammation: toll-like receptors," Free Radical Biology \& Medicine, vol. 48, no. 9, pp. 1121-1132, 2010.

[39] K. Tsubota, "Oxidative stress and inflammation: hypothesis for the mechanism of aging," Nippon Ganka Gakkai Zasshi, vol. 111, no. 3, pp. 193-206, 2007.

[40] J. Hanus, H. Zhang, Z. Wang, Q. Liu, Q. Zhou, and S. Wang, "Induction of necrotic cell death by oxidative stress in retinal pigment epithelial cells," Cell Death \& Disease, vol. 4, no. 12, article no. e965, 2013.

[41] H. B. Juel, C. Faber, S. G. Svendsen, A. N. Vallejo, and M. H. Nissen, "Inflammatory cytokines protect retinal pigment epithelial cells from oxidative stress-induced death," PLOS ONE, vol. 8, no. 5, Article ID e64619, 2013.

[42] D. Yang, S. G. Elner, Z.-M. Bian, G. O. Till, H. R. Petty, and V. M. Elner, "Pro-inflammatory cytokines increase reactive oxygen species through mitochondria and NADPH oxidase in cultured RPE cells," Experimental Eye Research, vol. 85, no. 4, pp. 462472, 2007.

[43] S. Ohira, T. Inoue, K. Shobayashi, K. Iwao, M. Fukushima, and H. Tanihara, "Simultaneous increase in multiple proinflammatory cytokines in the aqueous humor in neovascular glaucoma with and without intravitreal bevacizumab injection," Investigative Ophthalmology \& Visual Science, vol. 56, no. 6, pp. 3541-3548, 2015.

[44] P. Murugeswari, D. Shukla, A. Rajendran, R. Kim, P. Namperumalsamy, and V. Muthukkaruppan, "Proinflammatory cytokines and angiogenic and anti-angiogenic factors in vitreous of patients with proliferative diabetic retinopathy and eales' disease," Retina, vol. 28, no. 6, pp. 817-824, 2008.

[45] J. B. Jonas, Y. Tao, M. Neumaier, and P. Findeisen, "Cytokine concentration in aqueous humour of eyes with exudative agerelated macular degeneration," Acta Ophthalmologica, vol. 90, no. 5, pp. e381-e388, 2012.

[46] M. J. Koss, M. Pfister, F. Rothweiler et al., "Comparison of cytokine levels from undiluted vitreous of untreated patients with retinal vein occlusion," Acta Ophthalmologica, vol. 90, no. 2, pp. e98-e103, 2012.

[47] D. N. Granger, T. Vowinkel, and T. Petnehazy, "Modulation of the inflammatory response in cardiovascular disease," Hypertension, vol. 43, no. 5, pp. 924-931, 2004.

[48] H. Wang, X. Han, E. S. Wittchen, and M. E. Hartnett, “TNF- $\alpha$ mediates choroidal neovascularization by upregulating VEGF expression in RPE through ROS-dependent $\beta$-catenin activation," Molecular Vision, vol. 22, pp. 116-128, 2016.

[49] T. Maraldi, C. Prata, C. Caliceti et al., "VEGF-induced ROS generation from $\mathrm{NAD}(\mathrm{P}) \mathrm{H}$ oxidases protects human leukemic cells from apoptosis," International Journal of Oncology, vol. 36, no. 6, pp. 1581-1589, 2010.

[50] A. Rosa, M. Ballarino, A. Sorrentino et al., "The interplay between the master transcription factor PU.1 and miR-424 regulates human monocyte/macrophage differentiation," Proceedings of the National Academy of Sciences of the United States of America, vol. 104, no. 50, pp. 19849-19854, 2007.

[51] S. Sarkar, B. K. Dey, and A. Dutta, "MiR-322/424 and -503 are induced during muscle differentiation and promote cell cycle quiescence and differentiation by down-regulation of Cdc25A," Molecular Biology of the Cell, vol. 21, no. 13, pp. 2138-2149, 2010.

[52] G. Ghosh, I. V. Subramanian, N. Adhikari et al., "Hypoxiainduced microRNA-424 expression in human endothelial cells regulates HIF- $\alpha$ isoforms and promotes angiogenesis," Journal of Clinical Investigation, vol. 120, no. 11, pp. 4141-4154, 2010.
[53] T. P. Cash, Y. Pan, and M. C. Simon, "Reactive oxygen species and cellular oxygen sensing," Free Radical Biology and Medicine, vol. 43, no. 9, pp. 1219-1225, 2007.

[54] X. Zhang, Y. Fu, X. Xu et al., "PERK pathway are involved in NO-induced apoptosis in endothelial cells cocultured with RPE under high glucose conditions," Nitric Oxide, vol. 40, pp. 10-16, 2014.

[55] Z. Sun, S. Zhang, J. Y. Chan, and D. D. Zhang, "Keap1 controls postinduction repression of the Nrf2-mediated antioxidant response by escorting nuclear export of Nrf2," Molecular and Cellular Biology, vol. 27, no. 18, pp. 6334-6349, 2007.

[56] T. Iso, T. Suzuki, L. Baird, and M. Yamamoto, "Absolute amounts and status of the Nrf2-Keap1-Cul3 complex within cells," Molecular and Cellular Biology, vol. 36, no. 24, pp. 31003112, 2016.

[57] A. T. Dinkova-Kostova, W. D. Holtzclaw, and T. W. Kensler, "The role of Keap1 in cellular protective responses," Chemical Research in Toxicology, vol. 18, no. 12, pp. 1779-1791, 2005.

[58] M. Kobayashi and M. Yamamoto, "Nrf2-Keap1 regulation of cellular defense mechanisms against electrophiles and reactive oxygen species," Advances in Enzyme Regulation, vol. 46, no. 1, pp. 113-140, 2006.

[59] C. Espinosa-Diez, V. Miguel, D. Mennerich et al., "Antioxidant responses and cellular adjustments to oxidative stress," Redox Biology, vol. 6, pp. 183-197, 2015.

[60] P. George, "Reaction between catalase and hydrogen peroxide," Nature, vol. 159, no. 4028, pp. 41-43, 1947.

[61] I. Fridovich, "Superoxide dismutases: defence against endogenous superoxide radical," Ciba Foundation symposium, no. 65, pp. 77-93, 1978.

[62] D. Siegel, D. L. Gustafson, D. L. Dehn et al., "NAD(P)H:quinone oxidoreductase 1: role as a superoxide scavenger," Molecular Pharmacology, vol. 65, no. 5, pp. 1238-1247, 2004.

[63] R. Sharma, Y. Yang, A. Sharma, S. Awasthi, and Y. C. Awasthi, "Antioxidant role of glutathione S-transferases: protection against oxidant toxicity and regulation of stress-mediated apoptosis," Antioxidants \& Redox Signaling, vol. 6, no. 2, pp. 289-300, 2004.

[64] R. Tenhunen, H. S. Marver, and R. Schmid, "Microsomal heme oxygenase. Characterization of the enzyme," Journal of Biological Chemistry, vol. 244, no. 23, pp. 6388-6394, 1969.

[65] R. Stocker, Y. Yamamoto, A. F. McDonagh, A. N. Glazer, and B. N. Ames, "Bilirubin is an antioxidant of possible physiological importance," Science, vol. 235, no. 4792, pp. 1043-1046, 1987.

[66] P. A. Lapchak, "A critical assessment of edaravone acute ischemic stroke efficacy trials: is edaravone an effective neuroprotective therapy?" Expert Opinion on Pharmacotherapy, vol. 11, no. 10, pp. 1753-1763, 2010.

[67] Y. Yamamoto, T. Kuwahara, K. Watanabe, and K. Watanabe, "Antioxidant activity of 3-methyl-1-phenyl-2-pyrazolin-5-one," Redox Report: Communications in Free Radical Research, vol. 2, no. 5, pp. 333-338, 1996.

[68] H. Yoshida, H. Yanai, Y. Namiki, K. Fukatsu-Sasaki, N. Furutani, and N. Tada, "Neuroprotective effects of edaravone: a novel free radical scavenger in cerebrovascular injury," CNS Drug Reviews, vol. 12, no. 1, pp. 9-20, 2006.

[69] H. Yoshida, K. Sasaki, Y. Namiki, N. Sato, and N. Tada, "Edaravone, a novel radical scavenger, inhibits oxidative modification of low-density lipoprotein (LDL) and reverses oxidized LDLmediated reduction in the expression of endothelial nitric oxide synthase," Atherosclerosis, vol. 179, no. 1, pp. 97-102, 2005. 
[70] T. Yamamoto, S. Yuki, T. Watanabe, M. Mitsuka, K.-I. Saito, and K. Kogure, "Delayed neuronal death prevented by inhibition of increased hydroxyl radical formation in a transient cerebral ischemia," Brain Research, vol. 762, no. 1-2, pp. 240-242, 1997.

[71] S. Murota, I. Morita, and N. Suda, "The control of vascular endothelial cell injury," Annals of the New York Academy of Sciences, vol. 598, no. 1, pp. 182-187, 1990.

[72] T. Watanabe, S. Yuki, M. Egawa, and H. Nishi, "Protective effects of MCI-186 on cerebral ischemia: possible involvement of free radical scavenging and antioxidant actions," The Journal of Pharmacology and Experimental Therapeutics, vol. 268, no. 3, pp. 1597-1604, 1994.

[73] Y. Inokuchi, S. Imai, Y. Nakajima et al., "Edaravone, a free radical scavenger, protects against retinal damage in vitro and in vivo," Journal of Pharmacology and Experimental Therapeutics, vol. 329, no. 2, pp. 687-698, 2009.

[74] T. Qin, L.-Y. Lei, N. Li, F. R. Shi, M.-H. Chen, and L. Xie, "Edaravone improves survival and neurological outcomes after CPR in a ventricular fibrillation model of rats," The American Journal of Emergency Medicine, vol. 34, no. 10, pp. 1944-1949, 2016.

[75] S. Amemiya, T. Kamiya, C. Nito et al., "Anti-apoptotic and neuroprotective effects of edaravone following transient focal ischemia in rats," European Journal of Pharmacology, vol. 516, no. 2, pp. 125-130, 2005.

[76] M. I. Roh, Y. Murakami, A. Thanos, D. G. Vavvas, and J. W. Miller, "Edaravone, an ROS scavenger, ameliorates photoreceptor cell death after experimental retinal detachment," Investigative Ophthalmology \& Visual Science, vol. 52, no. 6, pp. 3825-3831, 2011.

[77] Y. Yuan, H. Zha, P. Rangarajan, E.-A. Ling, and C. Wu, "Antiinflammatory effects of Edaravone and Scutellarin in activated microglia in experimentally induced ischemia injury in rats and in BV-2 microglia," BMC Neuroscience, vol. 15, article 125, 2014.

[78] Y. Nonaka, M. Shimazawa, S. Yoshimura, T. Iwama, and H. Hara, "Combination effects of normobaric hyperoxia and edaravone on focal cerebral ischemia-induced neuronal damage in mice," Neuroscience Letters, vol. 441, no. 2, pp. 224-228, 2008.

[79] T. Watanabe, M. Tahara, and S. Todo, "The novel antioxidant edaravone: from bench to bedside," Cardiovascular Therapeutics, vol. 26, no. 2, pp. 101-114, 2008.

[80] A. Gordois, H. Cutler, L. Pezzullo et al., "An estimation of the worldwide economic and health burden of visual impairment," Global Public Health, vol. 7, no. 5, pp. 465-481, 2012.

[81] W. L. Wong, X. Su, X. Li et al., "Global prevalence of age-related macular degeneration and disease burden projection for 2020 and 2040: a systematic review and meta-analysis," The Lancet Global Health, vol. 2, no. 2, pp. e106-e116, 2014.

[82] I. Bhutto and G. Lutty, "Understanding age-related macular degeneration (AMD): relationships between the photoreceptor/ retinal pigment epithelium/Bruch's membrane/choriocapillaris complex," Molecular Aspects of Medicine, vol. 33, no. 4, pp. 295317, 2012.

[83] M. L. Katz and W. G. Robison Jr., "What is lipofuscin? Defining characteristics and differentiation from other autofluorescent lysosomal storage bodies," Archives of Gerontology and Geriatrics, vol. 34, no. 3, pp. 169-184, 2002.

[84] L. S. Murdaugh, L. B. Avalle, S. Mandal et al., "Compositional studies of human RPE lipofuscin," Journal of Mass Spectrometry, vol. 45, no. 10, pp. 1139-1147, 2010.
[85] J. R. Sparrow and M. Boulton, "RPE lipofuscin and its role in retinal pathobiology," Experimental Eye Research, vol. 80, no. 5, pp. 595-606, 2005.

[86] T. R. Golden, D. A. Hinerfeld, and S. Melov, "Oxidative stress and aging: beyond correlation," Aging Cell, vol. 1, no. 2, pp. 117$123,2002$.

[87] S. Beatty, I. J. Murray, D. B. Henson, D. Carden, H.-H. Koh, and M. E. Boulton, "Macular pigment and risk for age-related macular degeneration in subjects from a Northern European population," Investigative Ophthalmology \& Visual Science, vol. 42, no. 2, pp. 439-446, 2001.

[88] A. Maeda, J. W. Crabb, and K. Palczewski, "Microsomal glutathione $S$-transferase 1 in the retinal pigment epithelium: protection against oxidative stress and a potential role in aging," Biochemistry, vol. 44, no. 2, pp. 480-489, 2005.

[89] T. Friedrichson, H. L. Kalbach, P. Buck, and F. J. G. M. van Kuijk, "Vitamin e in macular and peripheral tissues of the human Eye," Current Eye Research, vol. 14, no. 8, pp. 693-701, 1995.

[90] C. Castorina, A. Campisi, C. Di Giacomo, V. Sorrenti, A. Russo, and A. Vanella, "Lipid peroxidation and antioxidant enzymatic systems in rat retina as a function of age," Neurochemical Research, vol. 17, no. 6, pp. 599-604, 1992.

[91] S. Reeg and T. Grune, "Protein oxidation in aging: does it play a role in aging progression?" Antioxidants \& Redox Signaling, vol. 23, no. 3, pp. 239-255, 2015.

[92] M. Boulton, M. Rózanowska, and B. Rózanowski, "Retinal photodamage," Journal of Photochemistry and Photobiology B: Biology, vol. 64, no. 2-3, pp. 144-161, 2001.

[93] A. L. Wang, T. J. Lukas, M. Yuan, and A. H. Neufeld, "Increased mitochondrial DNA damage and down-regulation of DNA repair enzymes in aged rodent retinal pigment epithelium and choroid," Molecular Vision, vol. 14, pp. 644-651, 2008.

[94] S. G. Jarrett, A. S. Lewin, and M. E. Boulton, "The importance of mitochondria in age-related and inherited eye disorders," Ophthalmic Research, vol. 44, no. 3, pp. 179-190, 2010.

[95] J. V. Glenn and A. W. Stitt, "The role of advanced glycation end products in retinal ageing and disease," Biochimica et Biophysica Acta, vol. 1790, no. 10, pp. 1109-1116, 2009.

[96] Age-Related Eye Disease Study Research Group, "A randomized, placebo-controlled, clinical trial of high-dose supplementation with vitamins $\mathrm{C}$ and $\mathrm{E}$, beta carotene, and zinc for agerelated macular degeneration and vision loss: AREDS report no. 8," Archives of Ophthalmology (Chicago, Ill.: 1960), vol. 119, no. 10, pp. 1417-1436, 2001.

[97] J. Boyle, M. Vukicevic, K. Koklanis, and C. Itsiopoulos, "Experiences of patients undergoing anti-VEGF treatment for neovascular age-related macular degeneration: a systematic review," Psychology, Health \& Medicine, vol. 20, no. 3, pp. 296-310, 2015.

[98] R. Gaudana, H. K. Ananthula, A. Parenky, and A. K. Mitra, "Ocular drug delivery," The AAPS journal, vol. 12, no. 3, pp. 348360, 2010.

[99] D. R. Fintak, G. K. Shah, K. J. Blinder et al., "Incidence of endophthalmitis related to intravitreal injection of bevacizumab and ranibizumab," Retina, vol. 28, no. 10, pp. 1395-1399, 2008.

[100] J. O. Mason III, M. F. White, R. M. Feist et al., "Incidence of acute onset endophthalmitis following intravitreal bevacizumab (Avastin) injection," Retina, vol. 28, no. 4, pp. 564-567, 2008.

[101] S. Pilli, A. Kotsolis, R. F. Spaide et al., "Endophthalmitis associated with intravitreal anti-vascular endothelial growth 
factor therapy injections in an office setting," American Journal of Ophthalmology, vol. 145, no. 5, pp. 879-882, 2008.

[102] I. U. Scott and H. W. Flynn Jr., "Reducing the risk of endophthalmitis following intravitreal injections," Retina, vol. 27, no. 1, pp. 10-12, 2007.

[103] C. H. Meyer, S. Mennel, and N. Eter, "Incidence of endophthalmitis after intravitreal Avastin injection with and without postoperative topical antibiotic application," Der Ophthalmologe, vol. 104, no. 11, pp. 952-957, 2007.

[104] S. Imai, Y. Inokuchi, S. Nakamura, K. Tsuruma, M. Shimazawa, and H. Hara, "Systemic administration of a free radical scavenger, edaravone, protects against light-induced photoreceptor degeneration in the mouse retina," European Journal of Pharmacology, vol. 642, no. 1-3, pp. 77-85, 2010.

[105] H. Shimazaki, K. Hironaka, T. Fujisawa et al., "Edaravoneloaded liposome eyedrops protect against light-induced retinal damage in mice," Investigative Ophthalmology \& Visual Science, vol. 52, no. 10, pp. 7289-7297, 2011.

[106] T. Masuda, M. Shimazawa, S. Takata, S. Nakamura, K. Tsuruma, and H. Hara, "Edaravone is a free radical scavenger that protects against laser-induced choroidal neovascularization in mice and common marmosets," Experimental Eye Research, vol. 146, pp. 196-205, 2016.

[107] A. Wenzel, C. Grimm, M. Samardzija, and C. E. Remé, "Molecular mechanisms of light-induced photoreceptor apoptosis and neuroprotection for retinal degeneration," Progress in Retinal and Eye Research, vol. 24, no. 2, pp. 275-306, 2005.

[108] C. Grimm and C. E. Remé, "Light damage as a model of retinal degeneration," Methods in Molecular Biology, vol. 935, pp. 87-97, 2013.

[109] M. Niwa, H. Aoki, A. Hirata, H. Tomita, P. G. Green, and A. Hara, "Retinal cell degeneration in animal models," International Journal of Molecular Sciences, vol. 17, no. 1, article 110, 2016.

[110] K. Ojino, M. Shimazawa, Y. Ohno, T. Otsuka, K. Tsuruma, and H. Hara, "Protective effect of SUN N8075, a free radical scavenger, against excessive light-induced retinal damage in mice," Biological \& Pharmaceutical Bulletin, vol. 37, no. 3, pp. 424-430, 2014.

[111] T. Imamura, T. Hirayama, K. Tsuruma, M. Shimazawa, H. Nagasawa, and H. Hara, "Hydroxyl radicals cause fluctuation in intracellular ferrous ion levels upon light exposure during photoreceptor cell death," Experimental Eye Research, vol. 129, pp. 24-30, 2014.

[112] Y. Kuse, K. Ogawa, K. Tsuruma, M. Shimazawa, and H. Hara, "Damage of photoreceptor-derived cells in culture induced by light emitting diode-derived blue light," Scientific Reports, vol. 4, article 5223, 2014.

[113] S. Fuma, H. Murase, Y. Kuse, K. Tsuruma, M. Shimazawa, and H. Hara, "Photobiomodulation with $670 \mathrm{~nm}$ light increased phagocytosis in human retinal pigment epithelial cells," Molecular Vision, vol. 21, pp. 883-892, 2015.

[114] K. Tsuruma, M. Yamauchi, Y. Inokuchi, S. Sugitani, M. Shimazawa, and H. Hara, "Role of oxidative stress in retinal photoreceptor cell death in N-methyl-N-nitrosourea-treated mice," Journal of Pharmacological Sciences, vol. 118, no. 3, pp. 351-362, 2012.

[115] H. E. Grossniklaus, S. J. Kang, and L. Berglin, "Animal models of choroidal and retinal neovascularization," Progress in Retinal and Eye Research, vol. 29, no. 6, pp. 500-519, 2010.

[116] R. S. Shah, B. T. Soetikno, M. Lajko, and A. A. Fawzi, "A Mouse model for laser-induced choroidal neovascularization," Journal of Visualized Experiments, vol. 2015, no. 106, Article ID e53502, 2015.

[117] H. A. Quigley, “Glaucoma," The Lancet, vol. 377, no. 9774, pp. 1367-1377, 2011.

[118] H. A. Quigley, E. M. Addicks, W. R. Green, and A. E. Maumenee, "Optic nerve damage in human glaucoma: II. the site of injury and susceptibility to damage," Archives of Ophthalmology, vol. 99, no. 4, pp. 635-649, 1981.

[119] A. Izzotti, A. Bagnis, and S. C. Saccà, "The role of oxidative stress in glaucoma," Mutation Research-Reviews in Mutation Research, vol. 612, no. 2, pp. 105-114, 2006.

[120] R. F. Brubaker, "Delayed functional loss in glaucoma LII Edward Jackson Memorial Lecture," American Journal of Ophthalmology, vol. 121, no. 5, pp. 473-483, 1996.

[121] L. A. Levin, "Direct and indirect approaches to neuroprotective therapy of glaucomatous optic neuropathy," Survey of Ophthalmology, vol. 43, no. 1, pp. S98-S101, 1999.

[122] V. Zanon-Moreno, P. Marco-Ventura, A. Lleo-Perez et al., "Oxidative stress in primary open-angle glaucoma," Journal of Glaucoma, vol. 17, no. 4, pp. 263-268, 2008.

[123] R. Fernández-Durango, A. Fernández-Martínez, J. GarcíaFeijoo et al., "Expression of nitrotyrosine and oxidative consequences in the trabecular meshwork of patients with primary open-angle glaucoma," Investigative Ophthalmology \& Visual Science, vol. 49, no. 6, pp. 2506-2511, 2008.

[124] Y. Nakajima, Y. Inokuchi, M. Nishi, M. Shimazawa, K. Otsubo, and H. Hara, "Coenzyme Q10 protects retinal cells against oxidative stress in vitro and in vivo," Brain Research, vol. 1226, pp. 226-233, 2008.

[125] Y. Nakajima, Y. Inokuchi, M. Shimazawa, K. Otsubo, T. Ishibashi, and H. Hara, "Astaxanthin, a dietary carotenoid, protects retinal cells against oxidative stress in-vitro and in mice in-vivo," Journal of Pharmacy and Pharmacology, vol. 60, no. 10, pp. 1365-1374, 2008.

[126] Y. Nakajima, M. Shimazawa, K. Otsubo, T. Ishibashi, and H. Hara, "Zeaxanthin, a retinal carotenoid, protects retinal cells against oxidative stress," Current Eye Research, vol. 34, no. 4, pp. 311-318, 2009.

[127] M. Shimazawa, Y. Nakajima, Y. Mashima, and H. Hara, "Docosahexaenoic acid (DHA) has neuroprotective effects against oxidative stress in retinal ganglion cells," Brain Research, vol. 1251, pp. 269-275, 2009.

[128] R. A. Honkanen, S. Baruah, M. B. Zimmerman et al., "Vitreous amino acid concentrations in patients with glaucoma undergoing vitrectomy," Archives of Ophthalmology, vol. 121, no. 2, pp. 183-188, 2003.

[129] M. Almasieh, A. M. Wilson, B. Morquette, J. L. Cueva Vargas, and A. Di Polo, "The molecular basis of retinal ganglion cell death in glaucoma," Progress in Retinal and Eye Research, vol. 31, no. 2, pp. 152-181, 2012.

[130] G. Y. X. Kong, N. J. Van Bergen, I. A. Trounce, and J. G. Crowston, "Mitochondrial dysfunction and glaucoma," Journal of Glaucoma, vol. 18, no. 2, pp. 93-100, 2009.

[131] S. C. Saccà and A. Izzotti, "Oxidative stress and glaucoma: injury in the anterior segment of the eye," Progress in Brain Research, vol. 173, pp. 385-407, 2008.

[132] S. M. Ferreira, S. F. Lerner, R. Brunzini, P. A. Evelson, and S. F. Llesuy, "Oxidative stress markers in aqueous humor of glaucoma patients," American Journal of Ophthalmology, vol. 137, no. 1, pp. 62-69, 2004. 
[133] A. Goyal, A. Srivastava, R. Sihota, and J. Kaur, "Evaluation of oxidative stress markers in aqueous humor of primary open angle glaucoma and primary angle closure glaucoma patients," Current Eye Research, vol. 39, no. 8, pp. 823-829, 2014.

[134] A. A. Ghanem, L. F. Arafa, and A. El-Baz, "Oxidative stress markers in patients with primary open-angle glaucoma," Current Eye Research, vol. 35, no. 4, pp. 295-301, 2010.

[135] P. Chaudhary, F. Ahmed, and S. C. Sharma, "MK801-a neuroprotectant in rat hypertensive eyes," Brain Research, vol. 792, no. 1, pp. 154-158, 1998.

[136] L. Guo, T. E. Salt, A. Maass et al., "Assessment of neuroprotective effects of glutamate modulation on glaucoma-related retinal ganglion cell apoptosis in vivo," Investigative Ophthalmology \& Visual Science, vol. 47, no. 2, pp. 626-633, 2006.

[137] Y. H. Yücel, N. Gupta, Q. Zhang, A. P. Mizisin, M. W. Kalichman, and R. N. Weinreb, "Memantine protects neurons from shrinkage in the lateral geniculate nucleus in experimental glaucoma," Archives of Ophthalmology, vol. 124, no. 2, pp. 217225, 2006.

[138] M.-L. Ko, D.-N. Hu, R. Ritch, S. C. Sharma, and C.-F. Chen, "Patterns of retinal ganglion cell survival after brain-derived neurotrophic factor administration in hypertensive eyes of rats," Neuroscience Letters, vol. 305, no. 2, pp. 139-142, 2001.

[139] S. D. Crish and D. J. Calkins, "Neurodegeneration in glaucoma: progression and calcium-dependent intracellular mechanisms," Neuroscience, vol. 176, pp. 1-11, 2011.

[140] H. Yamada, Y.-N. Chen, M. Aihara, and M. Araie, "Neuroprotective effect of calcium channel blocker against retinal ganglion cell damage under hypoxia," Brain Research, vol. 1071, no. 1, pp. 75-80, 2006.

[141] E. Yoles, L. A. Wheeler, and M. Schwartz, " $\alpha 2$-adrenoreceptor agonists are neuroprotective in a rat model of optic nerve degeneration," Investigative Ophthalmology \& Visual Science, vol. 40, no. 1, pp. 65-73, 1999.

[142] M. Mckibbin and M. J. Menage, "The effect of once-daily latanoprost on intraocular pressure and pulsatile ocular blood flow in normal tension glaucoma," Eye, vol. 13, no. 1, pp. 31-34, 1999.

[143] A. H. Neufeld, A. Sawada, and B. Becker, "Inhibition of nitricoxide synthase 2 by aminoguanidine provides neuroprotection of retinal ganglion cells in a rat model of chronic glaucoma," Proceedings of the National Academy of Sciences of the United States of America, vol. 96, no. 17, pp. 9944-9948, 1999.

[144] H. V. Danesh-Meyer and L. A. Levin, "Neuroprotection: extrapolating from neurologic diseases to the eye," American Journal of Ophthalmology, vol. 148, no. 2, pp. 186.e2-191.e2, 2009.

[145] T. Aung, F. T. S. Oen, H.-T. Wong et al., "Randomised controlled trial comparing the effect of brimonidine and timolol on visual field loss after acute primary angle closure," British Journal of Ophthalmology, vol. 88, no. 1, pp. 88-94, 2004.

[146] A. K. Stout, H. M. Raphael, B. I. Kanterewicz, E. Klann, and I. J. Reynolds, "Glutamate-induced neuron death requires mitochondrial calcium uptake," Nature Neuroscience, vol. 1, no. 5, pp. 366-373, 1998.

[147] T. Nakazawa, "Mechanism of N-methyl-D-aspartate-induced retinal ganglion cell death," Nippon Ganka Gakkai zasshi, vol. 113, no. 11, pp. 1060-1070, 2009.

[148] A. T. Aksar, N. Yuksel, M. Gok, M. Cekmen, and Y. Caglar, "Neuroprotective effect of edaravone in experimental glaucoma model in rats: a immunofluorescence and biochemical analysis," International Journal of Ophthalmology, vol. 8, no. 2, pp. 239244, 2015.
[149] K. Hironaka, Y. Inokuchi, T. Fujisawa et al., "Edaravoneloaded liposomes for retinal protection against oxidative stressinduced retinal damage," European Journal of Pharmaceutics and Biopharmaceutics, vol. 79, no. 1, pp. 119-125, 2011.

[150] E. L. Feldman, "Oxidative stress and diabetic neuropathy: a new understanding of an old problem," Journal of Clinical Investigation, vol. 111, no. 4, pp. 431-433, 2003.

[151] M. Brownlee, "The pathobiology of diabetic complications: a unifying mechanism," Diabetes, vol. 54, no. 6, pp. 1615-1625, 2005.

[152] R. Varma, G. L. Macias, M. Torres et al., "Biologic risk factors associated with diabetic retinopathy: the Los Angeles Latino Eye Study," Ophthalmology, vol. 114, no. 7, pp. 1332-1340, 2007.

[153] Y. Wu, L. Tang, and B. Chen, "Oxidative stress: implications for the development of diabetic retinopathy and antioxidant therapeutic perspectives," Oxidative Medicine and Cellular Longevity, vol. 2014, Article ID 752387, 12 pages, 2014.

[154] X. Du, T. Matsumura, D. Edelstein et al., "Inhibition of GAPDH activity by poly(ADP-ribose) polymerase activates three major pathways of hyperglycemic damage in endothelial cells," The Journal of Clinical Investigation, vol. 112, no. 7, pp. 1049-1057, 2003.

[155] R. Mortuza, S. Chen, B. Feng, S. Sen, and S. Chakrabarti, "High glucose induced alteration of SIRTs in endothelial cells causes rapid aging in a p300 and FOXO regulated pathway," PLOS ONE, vol. 8, no. 1, Article ID e54514, 2013.

[156] R. Liu, H. Liu, Y. Ha, R. G. Tilton, and W. Zhang, "Oxidative stress induces endothelial cell senescence via downregulation of Sirt6," BioMed Research International, vol. 2014, Article ID 902842, 13 pages, 2014.

[157] T. Kietzmann and A. Görlach, "Reactive oxygen species in the control of hypoxia-inducible factor-mediated gene expression," Seminars in Cell \& Developmental Biology, vol. 16, no. 4-5, pp. 474-486, 2005.

[158] K. D. Mansfield, R. D. Guzy, Y. Pan et al., "Mitochondrial dysfunction resulting from loss of cytochrome c impairs cellular oxygen sensing and hypoxic HIF- $\alpha$ activation," Cell Metabolism, vol. 1, no. 6, pp. 393-399, 2005.

[159] N. S. Chandel, E. Maltepe, E. Goldwasser, C. E. Mathieu, M. C. Simon, and P. T. Schumacker, "Mitochondrial reactive oxygen species trigger hypoxia-induced transcription," Proceedings of the National Academy of Sciences of the United States of America, vol. 95, no. 20, pp. 11715-11720, 1998.

[160] M. Kuroki, E. E. Voest, S. Amano et al., "Reactive oxygen intermediates increase vascular endothelial growth factor expression in vitro and in vivo," The Journal of Clinical Investigation, vol. 98, no. 7, pp. 1667-1675, 1996.

[161] H. Izuta, N. Matsunaga, M. Shimazawa, T. Sugiyama, T. Ikeda, and H. Hara, "Proliferative diabetic retinopathy and relations among antioxidant activity, oxidative stress, and VEGF in the vitreous body," Molecular Vision, vol. 16, pp. 130-136, 2010.

[162] R. Recchioni, F. Marcheselli, F. Moroni, and C. Pieri, "Apoptosis in human aortic endothelial cells induced by hyperglycemic condition involves mitochondrial depolarization and is prevented by N-acetyl-L-cysteine," Metabolism: Clinical and Experimental, vol. 51, no. 11, pp. 1384-1388, 2002.

[163] M. Sasaki, Y. Ozawa, T. Kurihara et al., "Neurodegenerative influence of oxidative stress in the retina of a murine model of diabetes," Diabetologia, vol. 53, no. 5, pp. 971-979, 2010.

[164] Y. Ozawa, T. Kurihara, M. Sasaki et al., "Neural degeneration in the retina of the streptozotocin-induced type 1 diabetes model," 
Experimental Diabetes Research, vol. 2011, Article ID 108328, 7 pages, 2011.

[165] The Diabetic Retinopathy Study Research Group, "Preliminary report on effects of photocoagulation therapy," American Journal of Ophthalmology, vol. 81, no. 4, pp. 383-396, 1976.

[166] Early Treatment Diabetic Retinopathy Study Research Group, "Early Treatment Diabetic Retinopathy Study design and baseline patient characteristics. ETDRS report number 7," Ophthalmology, vol. 98, no. 5, supplement, pp. 741-756, 1991.

[167] P. Mitchell, F. Bandello, U. Schmidt-Erfurth et al., "The RESTORE study: ranibizumab monotherapy or combined with laser versus laser monotherapy for diabetic macular edema," Ophthalmology, vol. 118, no. 4, pp. 615-625, 2011.

[168] J.-F. Korobelnik, D. V. Do, U. Schmidt-Erfurth et al., "Intravitreal aflibercept for diabetic macular edema," Ophthalmology, vol. 121, no. 11, pp. 2247-2254, 2014.

[169] J. A. Wells, A. R. Glassman, A. R. Ayala et al., "Aflibercept, bevacizumab, or ranibizumab for diabetic macular edema," New England Journal of Medicine, vol. 372, no. 13, pp. 1193-1203, 2015.

[170] D. Yuan, Y. Xu, H. Hang et al., "Edaravone protect against retinal damage in streptozotocin-induced diabetic mice," PLoS ONE, vol. 9, no. 6, Article ID e99219, 2014.

[171] O. Peters, T. Back, U. Lindauer et al., "Increased formation of reactive oxygen species after permanent and reversible middle cerebral artery occlusion in the rat," Journal of Cerebral Blood Flow and Metabolism, vol. 18, no. 2, pp. 196-205, 1998.

[172] T. Inagaki, T. Akiyama, C.-K. Du, D.-Y. Zhan, M. Yoshimoto, and M. Shirai, "Monoamine oxidase-induced hydroxyl radical production and cardiomyocyte injury during myocardial ischemia-reperfusion in rats," Free Radical Research, vol. 50, no. 6, pp. 645-653, 2016.

[173] M. Becatti, R. Marcucci, A. M. Gori et al., "Erythrocyte oxidative stress is associated with cell deformability in patients with retinal vein occlusion," Journal of Thrombosis and Haemostasis, vol. 14, no. 11, pp. 2287-2297, 2016.

[174] N. Angayarkanni, S. Barathi, T. Seethalakshmi et al., "Serum PON1 arylesterase activity in relation to hyperhomocysteinaemia and oxidative stress in young adult central retinal venous occlusion patients," Eye, vol. 22, no. 7, pp. 969-974, 2008.

[175] R. S. Kotwal, F. K. Butler Jr., C. K. Murray, G. J. Hill, J. C. Rayfield, and E. A. Miles, "Central retinal vein occlusion in an Army Ranger with glucose-6-phosphate dehydrogenase deficiency," Journal of Special Operations Medicine, vol. 9, no. 3, pp. 59-638, 2009.

[176] S. Simoncini, C. Sapet, L. Camoin-Jau et al., "Role of reactive oxygen species and p38 MAPK in the induction of the proadhesive endothelial state mediated by IgG from patients with anti-phospholipid syndrome," International Immunology, vol. 17, no. 4, pp. 489-500, 2005.

[177] K.-C. Cheng, W.-C. Wu, and K.-J. Chen, "Intravitreal triamcinolone acetonide vs bevacizumab for treatment of macular oedema secondary to branch retinal vein occlusion," Eye, vol. 23, no. 11, pp. 2023-2033, 2009.

[178] H. Ogishima, S. Nakamura, T. Nakanishi et al., "Ligation of the pterygopalatine and external carotid arteries induces ischemic damage in the murine retina," Investigative Ophthalmology and Visual Science, vol. 52, no. 13, pp. 9710-9720, 2011.

[179] Y. Song, Y.-Y. Gong, Z.-G. Xie, C.-H. Li, Q. Gu, and X.-W. Wu, "Edaravone (MCI-186), a free radical scavenger, attenuates retinal ischemia/reperfusion injury in rats," Acta Pharmacologica Sinica, vol. 29, no. 7, pp. 823-828, 2008.
[180] T. Maeno, R. Tano, H. Takenaka, and T. Mano, "Edaravone (MCI-186) is effective as a free radical scavenger following arteriovenous sheathotomy for treatment of macular oedema associated with branch retinal vein occlusion," The British Journal of Ophthalmology, vol. 93, no. 11, pp. 1479-1482, 2009. 


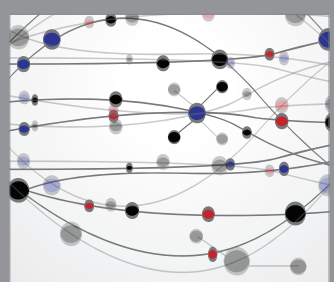

The Scientific World Journal
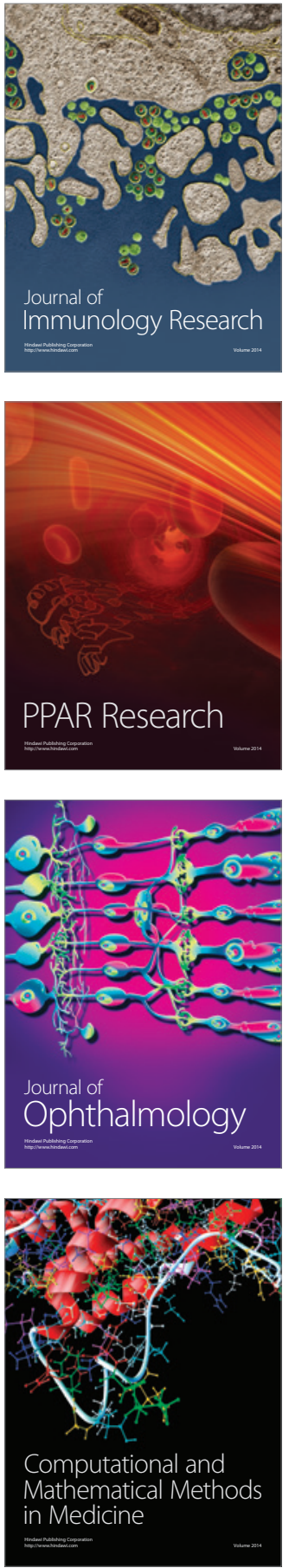

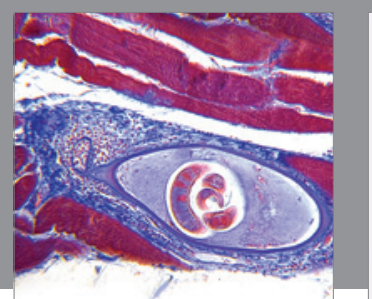

Gastroenterology Research and Practice
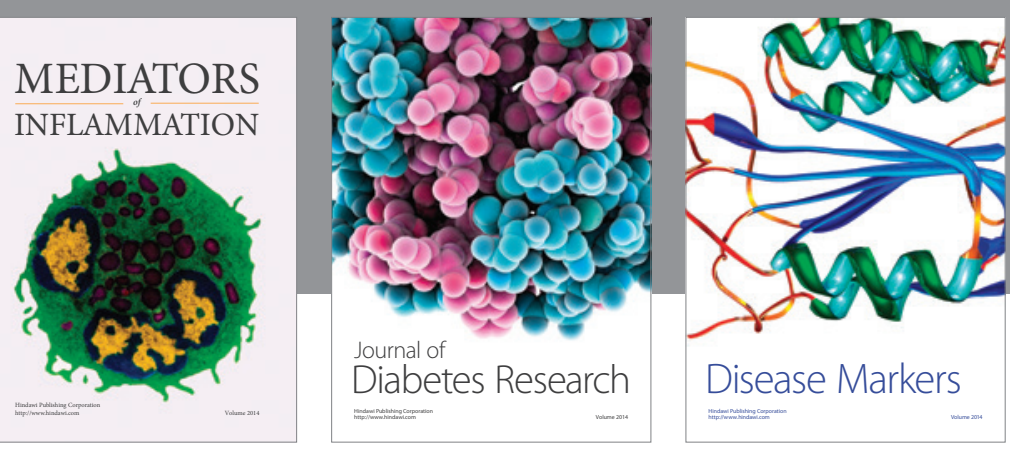

Disease Markers

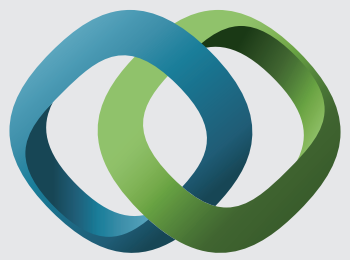

\section{Hindawi}

Submit your manuscripts at

https://www.hindawi.com
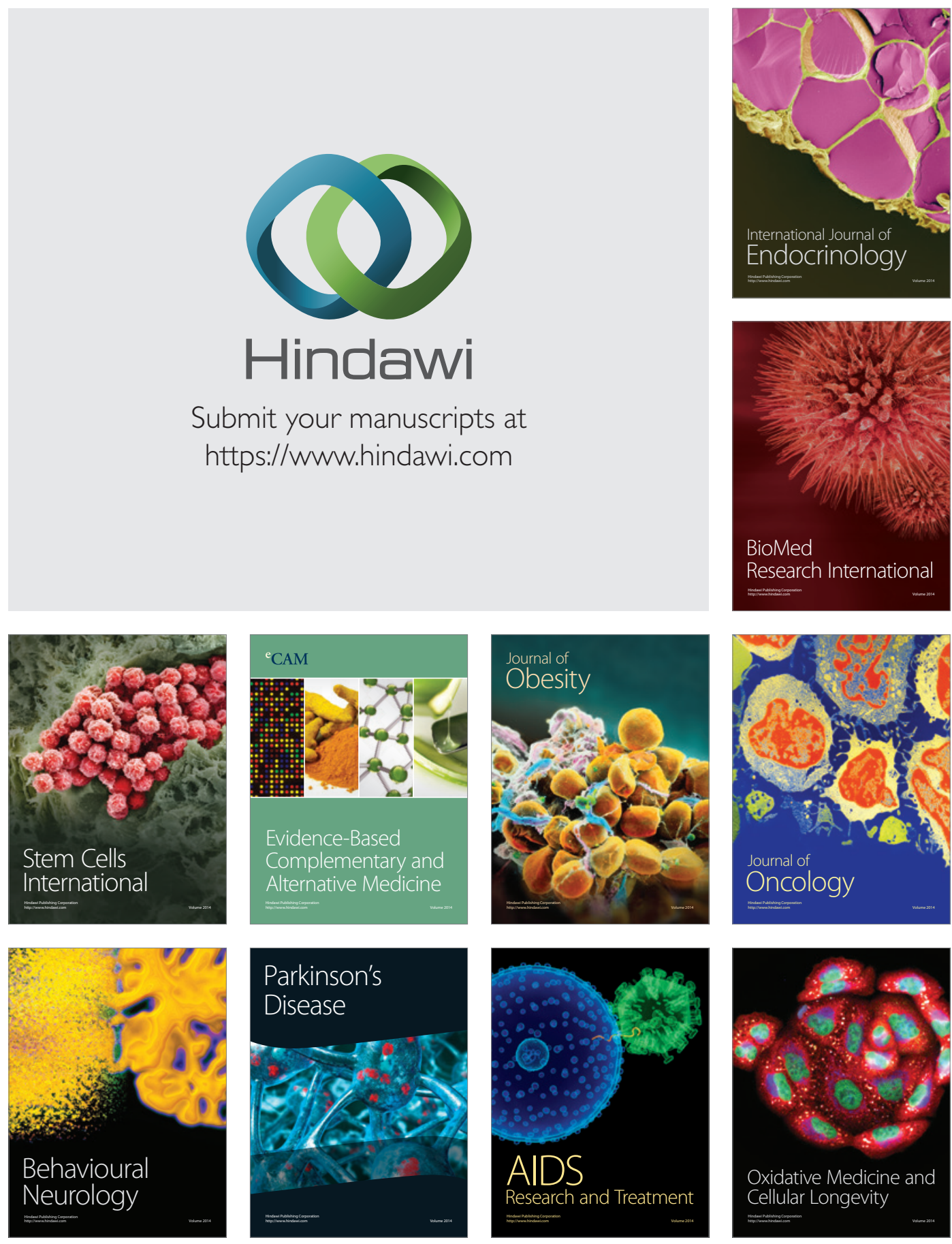